\title{
MODELAGEM, SIMULAÇÃO E DETECÇÃO DE FALHAS EM UM REATOR CSTR COM O USO DE RNA’S
}

\author{
L. C. BARRETO ${ }^{1}$, F. O. CARVALHO ${ }^{1}$, S. V. SARAIVA ${ }^{1}$, C. A. S. H. CAVALCANTI ${ }^{1}$ e P. \\ R. M. $\operatorname{COSTA}^{1}$
}

${ }^{1}$ Universidade Federal de Alagoas, Departamento de Engenharia Química E-mail para contato: lucascosta_108@hotmail.com

\begin{abstract}
RESUMO - Neste trabalho buscou-se a investigação do uso de RNA's (Redes Neurais Artificiais) como ferramenta para o desenvolvimento de sensores virtuais, e detecção de falhas em processos químicos. A RNA utilizada para a avaliação dos sensores virtuais foi a MLP (Multi-Layer Perceptron), para a detecção de falhas utilizou-se a MLP como classificação binária, bem como a rede Kohonen através da análise de mapas auto organizáveis (SOM Self-Organizing Map). Todavia, os dados utilizados nestas análises foram obtidos através da modelagem e simulação de uma reação de Van der Vussen em um reator CSTR, sendo assim, os dados obtidos em operação normal (sem falhas) foram utilizados na MLP para o desenvolvimento de sensores virtuais, os quais tem o objetivo de inferenciar variáveis do processo que são de difícil medição (como a concentração), através de informações de variáveis facilmente mensuráveis tais como: temperatura, vazão e calor. Todavia, para a etapa de detecção de falhas foram incrementados erros aleatórios (falhas) em algumas amostras de temperatura do reator, para testar a sensibilidade das redes na detecção de falhas. Os métodos utilizados nos casos supracitados conseguiram representar satisfatoriamente os processos estudados.
\end{abstract}

\section{INTRODUÇÃO}

A produção industrial aliada à competitividade tem se intensificado cada vez mais, sendo assim, há uma busca crescente por automatizações que facilitem o monitoramento operacional dos processos.

O avanço da tecnologia tornou possível à operação de processos cada vez mais complexos, possibilitando também uma maior amostragem em linha de dados inerentes às variáveis do processo, sendo assim, o tratamento matemático e/ou estatístico destes dados confere uma maior segurança e eficiência ao processo.

Devido à complexidade do desenvolvimento de modelos fenomenológicos, na maioria das vezes recorre-se a ferramentas computacionais para criação de modelos empíricos, os quais permitam a previsão do comportamento de um determinado processo, neste contexto, o uso de técnicas de inteligência artificial baseadas em aprendizado de máquina tais como as RNA's (Redes Neurais Artificiais) tem se destacado. Estas técnicas têm demonstrado eficiência quando utilizadas para a construção de sensores virtuais (os quais permitam inferenciar variáveis do processo), bem como no desenvolvimento de estratégias para a detecção de falhas, através de agrupamento de dados. 
Conhecida também como modelo conexionista ou sistema de processamento paralelo distribuído ou até mesmo modelo caixa preta, as RNA's são baseadas em neurônios biológicos Segundo Werle (2012). Sendo assim, as RNA's se configuram como um modelo matemático baseado no comportamento neural de organismos inteligentes, com a capacidade de aprendizado através de exemplos, generalizando a informação aprendida. Existem inúmeros tipos de RNA's, porém neste trabalho enfatizou-se o uso das redes MLP (Multi Layer Perceptron) e Kohonen.

As redes MLP são compostas de camadas de entrada, saída e camadas ocultas. O número de neurônios de entrada e saída são definidos pelo problema a ser estudado, e o número de camadas ocultas é definido na solução do problema (BRANDÃO, 2010). Esta rede é baseada no conceito de aprendizado de máquina supervisionado, onde existe a presença de um professor externo, o qual fornece um conjunto de exemplos, compostos por um conjunto de entradas e suas respectivas saídas conhecidas, para que a máquina a partir desses exemplos possa extrair o conhecimento necessário, generalizando para futuras entradas as saídas esperadas. Segundo Marques (2011), as redes Perceptron de Multicamadas são computacionalmente mais poderosas do que as redes sem camadas escondidas. Sendo assim, estas têm se destacado quando utilizadas para ajuste de funções e classificação.

Já a rede Kohonen ou Mapa Auto-organizável (SOM) é uma rede neural de aprendizado não supervisionado, no qual não há a necessidade de um professor externo, ou seja, não existe um conjunto de exemplos compostos por entradas e saídas previamente informados para que a máquina possa entender o domínio do problema, em outras palavras, o objetivo desta rede é encontrar padrões em conjuntos de dados complexos. Em sua forma mais simples, o algoritmo do SOM permite a visualização da similaridade de dados de alta dimensionalidade em uma matriz bidimensional (mapa de características) (Kohonen et al., 1996). Durante o treinamento, os vetores ou amostras de entrada que possuem semelhança são mapeados em regiões próximas no mapa, sendo assim, torna-se possível a visualização de clusters ou grupos, desta forma a rede Kohonen se torna útil em tarefas de detecção e isolamento de falhas em processos químicos, neste contexto, os clusters correspondem a amostras com falhas ou normais.

Neste trabalho utilizou-se a rede MLP como ajustadora de função (sensor virtual) e classificadora (detecção de falhas). Todavia, utilizou-se a rede Kohonen na clusterização (agrupamento) de dados para desenvolvimento de uma estratégia de detecção de falhas, utilizando os dados simulados no reator CSTR.

\section{METODOLOGIA}

\subsection{Modelo do Processo}

Na primeira etapa deste trabalho efetuou-se a modelagem e simulação de uma de Van de Vusse em um reator CSTR (Continous Stirred Tank Reactor), a Figura 1(a) apresenta um esquema deste tipo de reação, na qual há a transformação do ciclopentadieno (A) no produto 
ciclopentenol (B), paralelamente há a formação do diciclopentadieno (C) e do ciclopentanediol (D), reação descrita em Klatt e Engell (1998). A corrente de entrada do reator contém apenas o reagente A com uma concentração inicial $\mathrm{Ca}_{0}$ e as constantes de reação $(\mathrm{k})$ dependem exponencialmente da temperatura de acordo com a lei de Arrhenius. Desta forma, para a avaliação e geração de dados efetuou-se a modelagem e simulação computacional do reator CSTR, para isso, utilizou-se as condições operacionais e parâmetros descritos no trabalho de Jiří Vojtěšek (2008).

A Figura 1(b) apresenta o resultado da simulação realizada em estado dinâmico, a análise dos perfis de concentração e temperatura obtidos permite dizer que o modelo se comportou em consonância com o comportamento de um reator CSTR, destacando que foi atingido o estado estacionário.

Figura 1 - Resultado da simulação em estado dinâmico.

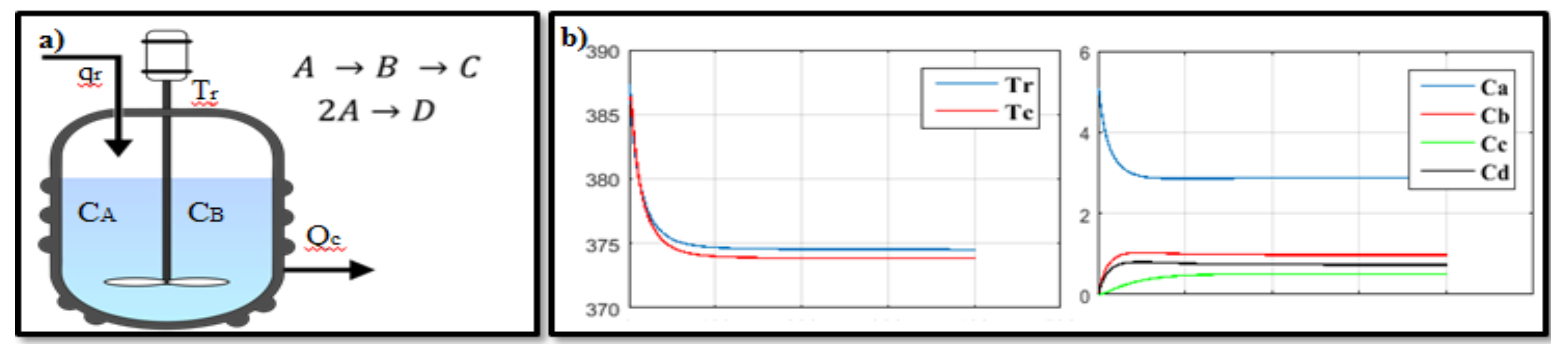

A partir do modelo desenvolvido foram simuladas 3030 condições de operação em estado estacionário através de variações na vazão de alimentação (qr) e no calor (Qc), estas forneceram dados de temperatura do reator $(\mathrm{Tr})$, concentração do reagente $\mathrm{A}(\mathrm{Ca})$ e concentração do produto $\mathrm{B}(\mathrm{Cb})$, estes dados foram utilizados para treinamento e validação das RNA's nas funções de ajuste de curva (analisador virtual), classificação e agrupamento de dados (detecção de falhas).

\subsection{Sensor Virtual}

$\mathrm{Na}$ segunda etapa deste trabalho buscou-se analisar o uso das técnicas de sistemas inteligentes, utilizando a RNA do tipo MLP (Multi-Layer Perceptron), através da interface Matlab®, como ferramenta ajustadora de funções, neste contexto esta rede funcionou como inferenciadora (soft sensor ou analisador virtual) da concentração do produto B, através de parâmetros que podem ser facilmente determinados como a temperatura do reator ( $\mathrm{Tr}$ ), vazão de alimentação (qr) e calor (Qc). Os dados de entrada (Tr, qr e $Q \mathrm{Qc}$ ) e saída $\left(\mathrm{C}_{\mathrm{B}}\right)$ são inseridos na rede para que esta possa aprender de que forma estes dados se relacionam, sendo assim, a rede pode inferenciar valores para a variável de interesse $\left(C_{B}\right)$ para novos dados de entrada.

Para esta etapa foram utilizadas as 3030 amostras da operação normal (sem falhas), sendo que $70 \%$ foram utilizados para treinamento (2120 amostras), $15 \%$ para teste (455 amostras) e os outros $15 \%$ para validação (455 dados). 


\subsection{Dados Para Detecção de Falhas}

Neste trabalhou considerou-se falhas de sensor de temperatura, a qual pode ser uma falha comum em um processo deste tipo. Do total de amostras geradas na etapa de simulação, foram selecionadas aleatoriamente 606 destas, nas quais foram inseridos distúrbios (falhas), os quais foram gerados através de um incremento de até $20 \%$ no valor da variável analisada (Tr). Desta forma, restaram 2424 amostras da operação normal (sem falhas). Sendo assim, tanto os dados com falhas como os sem falhas, foram inseridos na rede MLP (classificação) e na rede Kohonen, pra que se pudesse avaliar a sensibilidade destas na detecção e isolamento de falhas.

\section{RESULTADOS}

\subsection{Desenvolvimento do Sensor Virtual}

$\mathrm{Na}$ etapa de ajuste de função foram realizados diversos testes e os resultados obtidos para o melhor treinamento da rede estão representados na Figura 2.

Figura 2 - Resultados obtidos para MLP como sensor virtual.
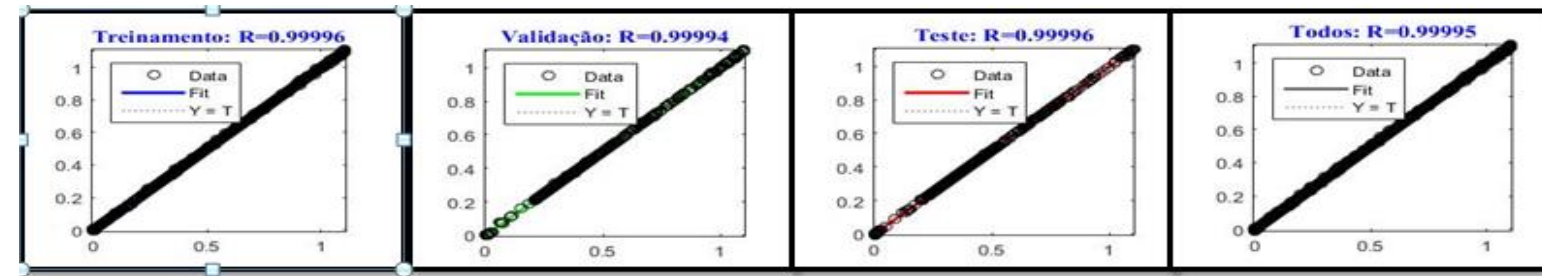

O resultado obtido para o coeficiente de regressão $(\mathrm{R})$ para todas as etapas (treinamento, validação, testes e todos os pontos), demonstra que o ajuste foi bem-sucedido. A análise do histograma de erro na Figura 3 demonstra que a maioria dos dados estão próximos da linha de erro zero. Tais análises demonstram que o treinamento da rede foi satisfatório, sendo assim esta pode ser utilizado como um analisador virtual. Deve-se salientar que os resultados foram muito bons, já que os dados tratados neste trabalho foram provenientes de simulação.

Figura 3 - Histograma de erro.

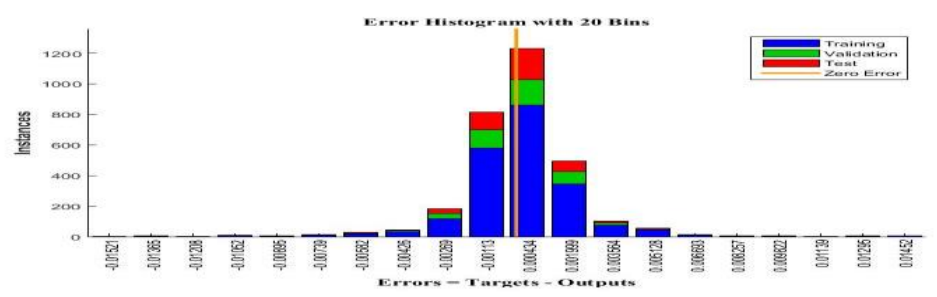

\subsection{Classificação com MLP}


Buscou-se a utilização da rede MLP na forma de classificação para avaliar através dos valores das variáveis de acompanhamento do processo ( $\mathrm{Tr}$, qr, Qc e $\mathrm{C}_{\mathrm{B}}$ ), se a rede é capaz de classificar e separar os dados normais dos dados com falhas previamente classificados de forma binária, desta forma os dados na operação normal foram classificados como [1 0 ] e os dados com falhas foram classificados como [0 1], os resultados obtidos nesta etapa são demostrados na Figura 4.

Figura 4 - Matriz de confusão para a rede usada como classificação.

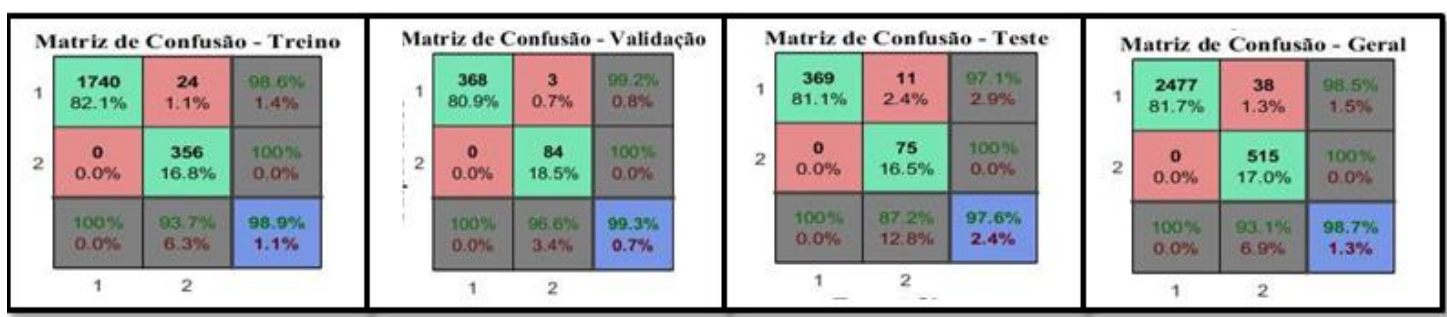

A análise da matriz de confusão para treino na Figura 4 permite concluir que 98,9\% dos dados foram classificados de forma correta, percebe-se também que 24 amostras $(1,1 \%)$ que deveriam pertencer à classe 1 , foram classificadas como classe 2 , estes dados são chamados de falso - positivo, desta forma, outros dados falso-positivo aparecem nas matrizes de validação, teste e geral. Isto se deve ao fato de que os valores dos dados em operação normal e com falhas tem certa proximidade. Por fim, pode-se perceber na Mariz de Confusão - Geral na Figura 4, que 98,7\% dos dados foram classificados de maneira correta. Desta forma, a rede conseguiu classificar de forma coerente os dados com falha e sem falha.

\subsection{Mapa Auto Organizável}

Os resultados obtidos com a rede Kohonen são expressos na Matriz U (matriz de distâncias) Figura 5, o mapa utilizado possui dimensões [10x6] totalizando um total de 60 neurônios.

Figura 5 - Matriz de distâncias.

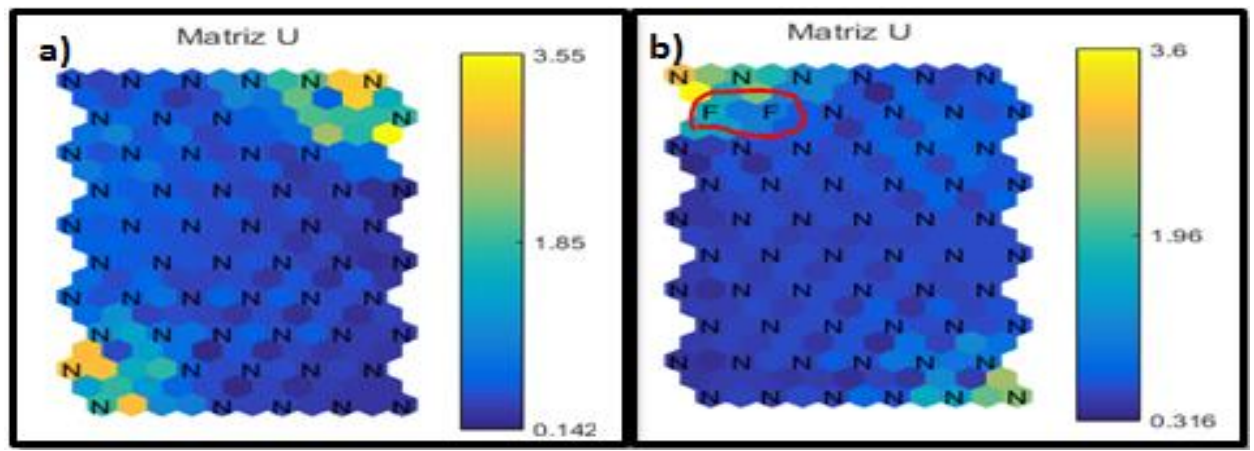

A análise da Figura 5(a) mostra que os dados de operação normal não formam um agrupamento uniforme, o esquema de cores indica que existem grandes valores de distâncias entre algumas amostras normais. A Figura 5(b) mostra que a rede conseguiu detectar e isolar as falhas (contornadas em vermelho) com sucesso, demonstrando sensibilidade neste aspecto. 


\section{CONCLUSÃO}

Neste trabalho foi demonstrada a construção de sensores virtuais, bem como, a estratégia para detecção de falhas em um reator CSTR através do uso das RNA's. A análise dos resultados obtidos permitiu concluir que a rede MLP demonstrou eficácia quando usada como sensor virtual inferenciando variáveis do processo, bem como quando utilizada na forma de classificação na detecção de falhas. Foi observado também que a rede Kohonen apresentou resultados satisfatórios tanto para a detecção das falhas quanto para o isolamento das mesmas, sendo assim o uso destas redes para este tipo de aplicação é promissor.

\section{REFERENCIAS}

BRANDÃO, M. M. S. L. Detecção e diagnóstico de falhas de processo químico dinâmico por redes neuronais multicamadas e mapas auto-organizáveis. 2010. 100p. Dissertação (Mestre em Ciências) - Universidade Federal do Rio de Janeiro. Rio de Janeiro - RJ

KLATT, K.U., ENGELL, S. Gain-scheduling trajectory control of a continuous stirred tank reactor. Computers \& Chemical Engineering, 491-502, 1998.

KOHONEN, T., OJA, E., SIMULA, O., VISA, A., KANGAS, J. Engineering Applications of the Self-organizing Map. Proceedings of the IEEE. 1996.

MARQUES, L. P.. Utilização de Redes Neurais Artificiais e Análise de Componentes Principais no Monitoramento da Qualidade da Água. Dissertação. Programa de PósGraduação em Engenharia Química - UFPE. Recife. 100f. 2011.

VOJTĚŠEK, J. Chemical Reactors: Modern Control Methods, 2007.

WERLE, L. O. Analisadores virtuais baseados em modelo neural para monitoramento e controle de colunas de destilação com aquecimento distribuído. 2012. 262 p. Tese de Doutorado (Doutor em Engenharia Química) - Universidade Federal de Santa Catarina. Santa Catarina - SC. 